\title{
CURSILLOS DE GEOGRAFIA DE ALTA MONTAÑA EN 1981
}

Organizado por la Sección de Geografía de la Diputación de la Rioja, y por el Instituto de Estudios Pirenáicos de Jaca, y dirigido por el Dr. José M. ${ }^{a}$ García-Ruiz, se llevó a cabo del 1 al 5 de julio de 1981 un Cursillo de Geografía de Alta Montaña. Contó con la presencia de un grupo de estudiantes de Geografía procedentes del Colegio Universitario de La Rioja y de la Universidad de Zaragoza, así como de algunos postgraduados.

Se llevaron a cabo amplios trabajos de campo con la finalidad de dar a conocer la cuenca alta de los ríos Arazas y Cinca, tanto desde un punto de vista físico (formación, morfología, materiales...) como humano (sistemas de vida e integración en el medio, ganadería...). Conviene destacar sobre todo el estudio pormenorizado llevado a cabo por parte del director del Cursillo y de M.A. Arbella León (Centro Pirenáico de Biología Experimental) sobre los modelos de erosión dominantes en los loess del Pirineo Central, para lo cual se estableció un pequeño campamento en el refugio de Góriz (2.160 m.) en la vertiente meridional de Monte Perdido. Se discutió su distribución y características y los factores y procesos que inician la erosión, pues se trata de un amplio sector de suelos profundos, cubiertos de pastos densos de elevada productividad estival y que acusan actualmente un rapidísimo proceso de degradación por erosión hídrica.

Asimismo, la Sección de Geografía de la Diputación de La Rioja en colaboración con el Departamento de Geografía del Colegio Universitario de La Rioja organizó un curso de Geografía de la Montaña en los días 19 al 22 de noviembre de 1981 en Ezcaray. Estuvo dirigido por el Dr. José M. a García Ruiz y por José Arnáez Vadillo y acogió a estudiantes del Colegio Universitario y de la Universidad de Zaragoza.

Toda la actividad del curso estuvo centrada en trabajo de campo con objeto de analizar las formas de relieve dominantes, la historia geológica y la evolución de vertientes en la Sierra de la Demanda. Así, se dedicó un día a realizar un corte desde el fondo del Valle del Oja hasta el pico del San Lorenzo, pasando por la estación de esquí de Valdezcaray, donde han comenzado a aparecer notables síntomas de erosión hídrica ligada a la gestión actual de las laderas y a la construcción de pistas. El segundo día se recorrió buena parte de la divi- 
soria de aguas de la Demanda, lo que permitió estudiar la superficie de erosión de cumbres y los circos glaciares con sus aparatos morrénicos. Finalmente, el día 22 se realizó una excursión por los valles periféricos de la Demanda para estudiar las formas de contacto entre el Paleozóico y el secundario. En todas las salidas se discutieron sobre el terreno todos aquellos aspectos humanos que venían sugeridos por la perspectiva de la vegetación y de la morfología agraria.

JOSE ARNAEZ-VADILLO 